\title{
ESTABILIDADE DA POLPA DO BACURI (Platonia insignis Mart.) CONGELADA POR 12 MESES
}

\author{
Stability of the bacuri pulp (Platonia insignis Mart.) frozen for 12 months
}

\author{
Virlane Kelly Lima da Silva ${ }^{1}$, Raimundo Wilane de Figueiredo², Edy Sousa de Brito ${ }^{3}$, Geraldo Arraes Maia², \\ Paulo Henrique Machado de Sousa², Evania Altina Teixeira de Figueiredo
}

\begin{abstract}
RESUMO
Conduziu-se este trabalho, com o objetivo de realizar o processamento e avaliar a estabilidade da polpa de bacuri (Platonia insignis Mart.) submetida ao congelamento durante 12 meses. Durante o período de armazenamento não ocorreram alterações significativas nas características físico-químicas da polpa quanto aos teores de sólidos solúveis, $\mathrm{pH}$, atividade de água, açúcares totais e redutores, vitamina $\mathrm{C}$, compostos fenólicos poliméricos e oligoméricos, pectina total e solúvel e cor $\mathrm{L}, \mathrm{a}^{*}, \mathrm{~b}^{*}$, enquanto que a acidez total e relação SST/AT variaram com o tempo de armazenamento. Os compostos fenólicos dímeros apresentaram aumento em função do tempo. Pelos resultados obtidos, a polpa de bacuri não pode ser considerada uma boa fonte de vitamina C. Por outro lado, apresenta baixos teores de compostos fenólicos caracterizando a polpa como, potencialmente pouco adstringente e com potencial para o processamento. A qualidade microbiológica não foi alterada durante o período de armazenamento. Os resultados apontam a eficiência do congelamento na manutenção das características físico-químicas e microbiológicas da polpa de bacuri.
\end{abstract}

Termos para indexação: Polpa de fruta, qualidade, características físico-químicas.

\section{ABSTRACT}

The objective of this work was to process and evaluate the stability of the bacuri (Platonia insignis Mart.) pulp submitted to freezing for 12 months. During the storage period there were significant changes in the physiochemical characteristics of the pulp as for the content of total soluble solids, $\mathrm{pH}$, water activity, total and reducing sugars, vitamin $\mathrm{C}$, polimer and oligomeric phenolic compounds, total and soluble pectin and color $\mathrm{L}$, the $\mathrm{a}^{*}, \mathrm{~b}{ }^{*}$, while total acidity and soluble solids varied with the storange period. The dimers phenolic compounds incresead with the time. According to the results, the bacuri pulp cannot be considered a good source of vitamin $\mathrm{C}$, but it presents low contents of phenolic compounds characterizing the pulp as little astringent, thus showing potential for the processing. The microbiological quality was not altered during the storage period indicating the efficiency of freezing for maintaining the physiochemical and microbiological characteristics of the bacuri pulp.

Index terms: Pulp of fruit, quality, physicochemical characteristics.

(Recebido em 30 de julho de 2008 e aprovado em 15 de julho de 2009)

\section{INTRODUÇÃO}

A fruticultura, de uma maneira geral, vem alcançando grande destaque no Brasil, não só pela importante alternativa de diversificação e aumento de renda para a pequena propriedade, como também pela geração de empregos por se tratar de uma atividade altamente agregadora de mão-de-obra e indutora da instalação de pólos agroindustriais.(Pereira et al, 2008).

O consumo de frutas e hortaliças tem aumentado principalmente em decorrência do seu valor nutritivo e efeitos terapêuticos. Esses alimentos contêm diferentes fitoquímicos, muitos dos quais possuem propriedades antioxidantes que podem estar relacionadas com o retardo do envelhecimento e com a prevenção de certas doenças como o câncer, acompanhado de doenças-crônicasinflamátórias, doenças cardíacas, pulmonares e problemas associados com o envelhecimento (Pieniz et al.2009).

O bacuri (Platonia insignis Mart.) é um fruto do tamanho de uma laranja, redondo, com casca grossa, e de cor amarelo-citrina, contendo polpa viscosa e muito saborosa. Seu fruto pode ser utilizado, tanto na forma in natura como para a agroindústria (Ferreira et al., 1987). O fruto apresenta grande potencial, tanto sob o ponto de vista do seu processamento industrial, como para o consumo in natura (Cavalcante, 1996), pelo seu sabor e aroma agradáveis, sendo muito utilizada na preparação de sorvetes, cremes, refrescos, compotas e geléias. No entanto, apesar da multiplicidade de uso, apenas a polpa

1Universidade Federal do Ceará/UFC - Cx. P. 60347-640 - Fortaleza, CE - virlanekelly@yahoo.com.br

${ }^{2}$ Universidade Federal do Ceará/UFC - Centro de Ciências Agrárias - Departamento de Tecnologia de Alimentos - Fortaleza, CE ${ }^{3}$ Empresa Brasileira de Pesquisa Agropecuaria Agroindústria Tropical - Fortaleza, CE 
tem sido utilizada de forma econômica, sendo o principal produto o néctar (Souza et al., 2000). A produção de bacuri é comercializada, principalmente, nas CEASAs e feiras livres de Belém-PA, São Luís-MA e Teresina-PI, e não tem sido suficiente para atender à demanda crescente do mercado consumidor dessas capitais. Na forma de polpa congelada, a comercialização é feita, principalmente, nas grandes redes de supermercados a preços superiores aos de outras frutas tropicais como o cupuaçu, o cajá, a goiaba e a graviola (Souza et al., 2000). Portanto, a médio ou a longo prazos, essa espécie pode estabelecer-se como uma nova e excelente alternativa para os mercados interno e externo de frutas.

Com a tecnologia disponível, o mercado de polpas de frutas congeladas tem tido um crescimento razoável e apresenta grande potencial mercadológico em função da variedade de frutas com sabores exóticos bastante agradáveis (Bueno et al., 2002). O congelamento tem a finalidade de preservar alimentos armazenados por longos períodos. Entretanto, alterações podem ocorrer mesmo a temperaturas abaixo de $0^{\circ} \mathrm{C}$. A velocidade em que o alimento foi congelado e a estabilidade da temperatura durante o armazenamento são fatores que auxiliam na estabilidade deste (Agostini-Costa et al., 2003; Yamashita et al., 2003).

Neste trabalho, objetivou-se realizar o estudo do processamento e avaliar a estabilidade físico-química e microbiológica da polpa de bacuri submetida ao congelamento durante 12 meses.

\section{MATERIAL E MÉTODOS}

Foram utilizados frutos de diferentes genótipos de bacurizeiro oriundos da localidade de Afonso Cunha, Estado do Maranhão, Região Meio-Norte do Brasil. Os frutos, fisiologicamente maduros, foram colhidos em fevereiro de 2006, acondicionados em isopor e transportados por via terrestre ao Laboratório de Processos Agroindustriais da Embrapa Agroindústria Tropical, em Fortaleza-Ceará, onde foram imediatamente processados para a obtenção da polpa. Os frutos foram recebidos, pesados e classificados quanto aos seus atributos de qualidade (uniformidade na cor amarela da casca, perfeita integridade física, isenção de doenças, grau de maturação, sendo escolhidos os frutos maduros). Com intuito de retirar as sujidades mais grosseiras, os frutos foram previamente lavados com água potável. Em seguida, os frutos foram imersos em água clorada (200 ppm de cloro) durante 20 minutos, com o objetivo de reduzir a carga microbiana. A pesagem foi realizada em balança da marca Toledo, Modelo 2096, com carga mínima de 250 g e máxima de 50 kg, com a finalidade de determinar o rendimento da extração da polpa.
Os frutos foram então cortados manualmente com o auxílio de facas para a retirada da casca e das sementes. O material obtido foi submetido ao despolpamento com o uso de uma despolpadeira da marca Bonina, Modelo 0,25 df A8, da Marca Itametal sendo essa polpa dividida em três lotes de aproximadamente $4 \mathrm{~kg}$, envasadas em sacos de polietileno $12 \times 26 \mathrm{~cm}$ e $0,20 \mathrm{~mm}$ de espessura, com capacidade de $100 \mathrm{~g}$, e armazenados sob congelamento a $-20^{\circ} \mathrm{C}$ para análises físico-químicas e microbiológicas. A polpa foi armazenada durante 12 meses, sendo coletadas amostras para avaliação a cada 30 dias. Todas as análises foram realizadas na polpa descongelada.

As análises físico-químicas realizadas constaram de rendimento da polpa obtido pela diferença entre a massa do fruto [cascas, polpas e sementes $(\mathrm{g})$ ] e o das sementes $(\mathrm{g})$ e cascas $(\mathrm{g})$, dividindo-se pela massa total do fruto $(\mathrm{g})$. O resultado foi multiplicado por 100 e expresso em porcentagem. A cor instrumental foi determinada por reflectometria, utilizando-se calorímetro Minolta (Croma Meter CR-200b) calibrado em superfície de porcelana branca sob condições de iluminação, sendo expressa no módulo L a* b* (Hunterlab, 1996). O teor de sólidos solúveis (TSS) foi obtido por meio de leitura direta em refratômetro digital (ATAGO PR-101) de acordo com a metodologia recomendada pela Association of Official Analytical Chemistry - AOAC (1992). A acidez titulável (AT) determinada segundo metodologia do Brasil (2005), por meio de titulação com solução de $\mathrm{NaOH} 0,1 \mathrm{~N}$, e os resultados foram expressos em porcentagem de ácido cítrico. $\mathrm{O} \mathrm{pH}$ foi medido diretamente na polpa, utilizando um potenciômetro (Mettler, modelo DL 12), aferido com soluções tampões de pH 4 e 7 , conforme a AOAC (1992). A relação TSS/ATT foi obtida por meio do quociente entre as duas análises. A atividade de água foi realizada em aparelho digital AQUALAB da marca Decagon Devices Inc. EUA modelo CX-2 a temperatura de $20^{\circ} \mathrm{C}$, na polpa descongelada. Os teores de açúcares totais e redutores foram determinados pelo método de Miller (1959) utilizando o ácido 3-5 dinitrossalicílico (DNS). O teor de vitamina $\mathrm{C}$ foi obtido por titulometria direta com DFI (2,6 dicloro-fenol-indofenol $0,02 \%$ ) até coloração rósea clara permanente, de acordo com Strohecher \& Henning (1967). Para a determinação teor de compostos fenólicos a extração foi realizada de acordo com Swain \& Hills (1959) e a determinação conforme metodologia descrita por Reicher et al. (1981). Para a obtenção do extrato, tomou-se $1 \mathrm{~g}$ de polpa diluída em 25 $\mathrm{mL}$ de líquido extrator, metanol P.A, metanol $50 \%$ e água destilada para as formas dímeras, oligoméricas e poliméricas, respectivamente. Os resultados foram expressos em porcentagem. Os teores de pectina total e solúvel 
foram determinados espectrofotometricamente (Spectronic Genesys 2) a $520 \mathrm{~nm}$, segundo técnica de Blumenskrantz \& Asboe-Hansen (1973) utilizando-se o m-hidroxidifenil como cromógeno, após extração realizada de acordo com McCready \& McComb (1952), e os resultados foram expressos em percentagem.

As análises microbiológicas foram realizadas na polpa, para bolores e leveduras, coliformes a $35^{\circ} \mathrm{C} \mathrm{e} 45^{\circ} \mathrm{C}$, Salmonella sp. e microrganismos aeróbios mesófilos utilizando-se metodologia descrita pela American Public Health Association (American Public Health Association APHA, 2001).

Para a análise estatística dos dados, foi utilizado delineamento inteiramente casualisado. $\mathrm{O}$ efeito do tempo de armazenagem sobre as variáveis estudadas foi avaliado por meio da análise de regressão utilizando o programa estatístico SAEG (Universidade Federal de Viçosa, 2007), para que se obtivesse a curva que melhor descrevesse o comportamento dos dados. Os modelos estatísticos foram obtidos com base no coeficiente de determinação que foi padronizado como o mínimo 0,70 e na significância dos coeficientes das equações, por meio do $\mathrm{T}(\mathrm{P} \leq 0,05)$.

\section{RESULTADOS E DISCUSSÃO}

O rendimento em polpa de bacuri foi em média de $11,82 \%$, tais valores encontram-se dentro do intervalo reportado por Aguiar et al. (2008), cujas médias de polpa em diferentes matrizes de bacurizeiro variaram de 11,70 a $22,21 \%$. Os percentuais de polpa encontrados na literatura, em geral variam de 10 a 13\% (Cavalcante, 1996; Nazaré, 2000). Entretanto, Souza et al. (2001) reportaram frutos com 30,6 e 20,81\% de polpa, respectivamente. Segundo Chitarra \& Chitarra (2005), o elevado teor de polpa é uma das características mais desejáveis na comercialização de fruta in natura.

Os valores de $\mathrm{pH}$, de 3,22 a 3,48 e atividade de água de 0,987 a 0,994 (Tabela 1), apresentaram pequena variação, não diferindo estatisticamente com o tempo pela análise de regressão $(\mathrm{P}>0,05)$. Bezerra et al. (2006), estudando a polpa de bacuri "in natura" conservada por métodos combinados por meio da utilização dos seguintes obstáculos: adição de benzoato de sódio (1000 ppm) e metabissulfito de sódio (400 ppm), tratamento térmico $\left(100^{\circ} \mathrm{C} / 2 \mathrm{~min}\right.$.) e redução da atividade de água pela adição de sacarose, relatou valores de 0,985 para a atividade de água. Os valores de pH encontrados nesse estudo estão próximos aos encontrados na literatura por Bezerra et al. (2006), 3,12, Teixeira et al. (2001), 3,37; Aguiar et al. (2008) 3,07, Fontenele et al. (2010) 3,19.
Os teores de sólidos solúveis variaram de 13,27 a $14,83^{\circ}$ Brix (Tabela 1), diferindo estatisticamente ao nível de $5 \%$ de significância $(\mathrm{P}<0,05)$, não ocorrendo, todavia, ajuste da equação a nenhum modelo estatístico, por apresentarem baixos coeficientes de determinação $\left(R^{2}<0,70\right)$ e falta de ajustes significativos $(\mathrm{P}<0,05)$. Aguiar et al. (2008) encontrou valores médios de $12,19^{\circ}$ Brix, inferiores aos encontrados nesse estudo. Souza et al. (2001), estudando frutos do bacurizeiro oriundos do Maranhão e Piauí, constataram uma grande variação nos teores de sólidos solúveis, com valores de 9,54 a $20,87^{\circ}$ Brix, com média $\left(14,21^{\circ}\right.$ Brix) próxima aos do presente estudo.

Os resultados de acidez titulável podem ser úteis, visto que, esta variável é um importante determinante da qualidade do fruto para o consumo in natura e para o processamento industrial. Verificou-se ajuste a um modelo quadrático, decrescendo os valores de AT com o tempo de armazenamento (Figura 1).

Para a relação sólidos solúveis / acidez titulável pode se observar que houve uma variação nos valores encontrados, com médias variando de 5,09 a 9,93, ocorrendo diferença significativa ao nível de $5 \%$ de significância com o tempo de armazenamento (Figura 2).

De acordo com Chitarra \& Chitarra (2005), é por meio desta relação que se tem uma noção da influência da acidez sobre a doçura no paladar.

Os valores médios de açúcares totais e redutores da polpa variaram significativamente ao nível de 5\% com o tempo de armazenamento. Os açúcares totais variaram de 10,11 à $13,65 \%$, enquanto os açúcares redutores oscilaram de 7,38 à $8,72 \%$, porém não houve ajuste da regressão (Tabela 1). Teixeira et al. (2001) em estudos com frutos de bacurizeiro encontraram valores de açúcares totais próximos ao deste estudo, 10,98 e 11,06\%, respectivamente. Aguiar et al. (2008) encontrou valor médio de açúcares solúveis totais $(8,57 \%)$ e açúcares redutores, variando de 2,50 a $5,93 \%$, inferiores aos encontrados neste estudo.

Os teores de ácido ascórbico encontrados nesta pesquisa variaram de 3,96 a 1,76 mg $100 \mathrm{~g}^{-1}$ de polpa diferindo estatisticamente com o tempo de armazenamento ao nível de $5 \%$ de significância (Tabela 1), podendo ser ajustado a um modelo cúbico (Figura 3 ).

Pelos valores obtidos observa-se, uma diminuição nesses teores com o tempo de armazenamento. Aguiar et al. (2008) em seu estudo com diferentes matrizes de bacurizeiro relatou uma grande variação nos valores vitamina $\mathrm{C}$, de 2,40 a $14,38 \mathrm{mg} 100 \mathrm{~g}^{-1}$ de polpa (Tabela 1 ). De acordo com o observado neste trabalho e o reportado na literatura, o bacuri em geral é um fruto pobre em vitamina $C$, muito embora haja uma grande variação entre os teores 
apresentados por diversos autores. Isso pode ser confirmado por Alves et al. (2000), que relataram teor de vitamina $C$ na polpa de bacuri de no máximo $15,07 \mathrm{mg} 100 \mathrm{~g}^{-1}$, considerado muito baixo, se comparado ao de outras frutas. Fontenele et al. (2010), em seu estudo com bacuris armazenados sob condições de atmosfera modificada em temperatura ambiente e de refrigeração relatou média geral para vitamina $\mathrm{C}$, de $5,46 \mathrm{mg} 100 \mathrm{~g}^{-1}$ que está próximo ao

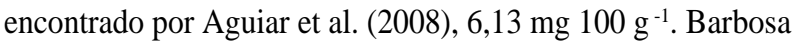
et al. (1979) também afirma que o teor de ácido ascórbico é considerado baixo, no entanto, sua industrialização não é impedida.

As substâncias pécticas são os principais componentes químicos dos tecidos relacionados com as

Tabela 1 - Médias de sólidos solúveis, vitamina $\mathrm{C}$, açúcares totais e redutores, $\mathrm{pH}, \mathrm{Aw}$, para a polpa de bacuri durante período de 360 dias de armazenamento.

\begin{tabular}{cccccc}
\hline Tempo (dias) & SS $\left({ }^{\circ}\right.$ Brix) $* *$ & $\begin{array}{c}\text { Açúcares totais } \\
(\%) * *\end{array}$ & $\begin{array}{c}\text { Açúcares } \\
\text { redutores }(\%) * *\end{array}$ & $\mathrm{pH}$ & Aw \\
\hline & & & & & \\
0 & $13,27 \pm 1,09$ & $11,63 \pm 0,08$ & $8,72 \pm 0,15$ & $3,16 \pm 0,20$ & $0,983 \pm 0,00$ \\
30 & $13,63 \pm 0,64$ & $11,80 \pm 0,08$ & $8,00 \pm 0,34$ & $3,39 \pm 0,00$ & $0,991 \pm 0,00$ \\
60 & $14,23 \pm 0,41$ & $11,37 \pm 0,31$ & $7,32 \pm 0,10$ & $3,52 \pm 0,05$ & $0,994 \pm 0,00$ \\
120 & $13,43 \pm 0,28$ & $11,30 \pm 0,18$ & $7,38 \pm 0,31$ & $3,43 \pm 0,01$ & $0,993 \pm 0,00$ \\
150 & $14,03 \pm 0,15$ & $11,12 \pm 0,69$ & $7,79 \pm 0,06$ & $3,44 \pm 0,00$ & $0,989 \pm 0,00$ \\
180 & $13,77 \pm 0,47$ & $11,07 \pm 0,12$ & $7,93 \pm 0,08$ & $3,47 \pm 0,01$ & $0,990 \pm 0,00$ \\
210 & $14,30 \pm 0,26$ & $10,11 \pm 0,34$ & $7,60 \pm 0,17$ & $3,44 \pm 0,00$ & $0,991 \pm 0,00$ \\
240 & $14,83 \pm 0,30$ & $12,75 \pm 0,71$ & $8,37 \pm 0,31$ & $3,44 \pm 0,01$ & $0,991 \pm 0,00$ \\
270 & $14,27 \pm 0,35$ & $13,65 \pm 0,07$ & $8,63 \pm 0,25$ & $3,48 \pm 0,00$ & $0,992 \pm 0,00$ \\
300 & $13,53 \pm 0,25$ & $12,03 \pm 0,13$ & $7,82 \pm 0,02$ & $3,47 \pm 0,02$ & $0,991 \pm 0,00$ \\
330 & $14,53 \pm 0,025$ & $11,68 \pm 0,07$ & $8,48 \pm 0,12$ & $3,48 \pm 0,01$ & $0,987 \pm 0,00$ \\
360 & $14,57 \pm 0,20$ & $12,83 \pm 0,17$ & $8,21 \pm 0,04$ & $3,42 \pm 0,03$ & $0,987 \pm 0,00$ \\
$\bar{X} \pm \sigma * *$ & $14,43 \pm 0,11$ & $11,79 \pm 0,12$ & $8,56 \pm 0,13$ & $3,37 \pm 0,03$ & $0,988 \pm 0,00$ \\
& $14,06 \pm 0,47$ & $11,78 \pm 0,87$ & $8,07 \pm 0,45$ & $3,43 \pm 0,08$ & $0,990 \pm 0,02$ \\
\hline
\end{tabular}

* valores médios obtidos das três repetições;

** diferiu significativamente durante o armazenamento $(\mathrm{p} \leq 0,05)$.

**** Média geral \pm desvio-padrão.

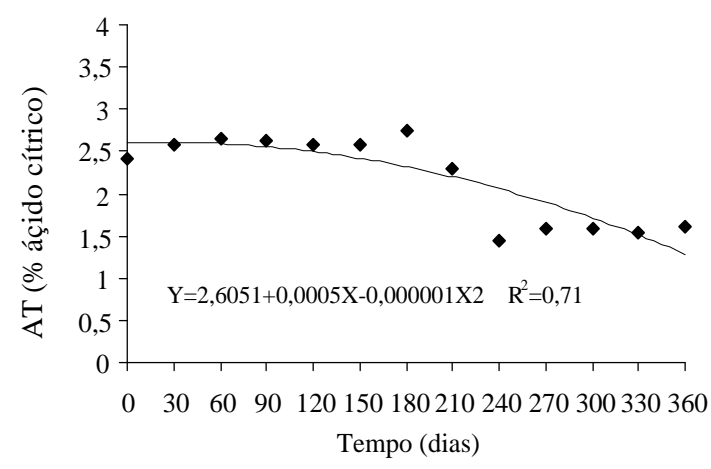

Figura 1 - Acidez titulável (AT) da polpa de congelada durante 12 meses.

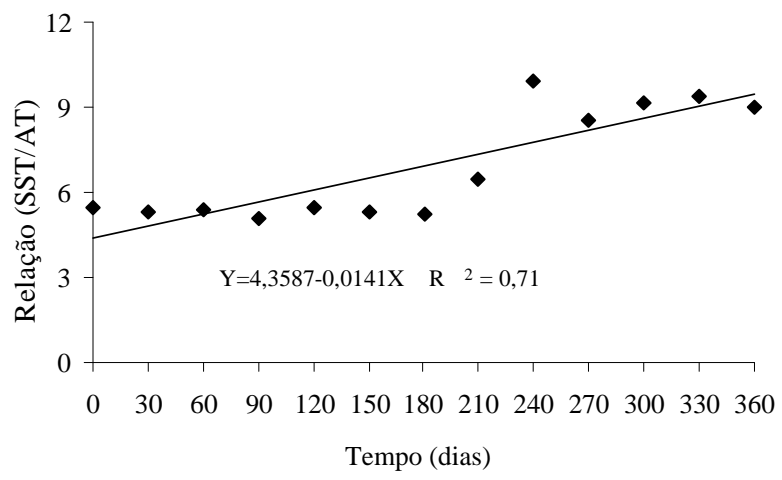

Figura 2 - Relação Sólidos solúveis/Acidez Total da polpa de bacuri congelada durante 12 meses. 
mudanças de textura dos frutos (Chitarra \& Chitarra, 2005). Os teores de pectina total variaram ao longo do armazenamento de $1,57 \%$ a $1,84 \%$ (Tabela 2), diferindo significativamente ao nível de $5 \%$ de significância $(\mathrm{p}<0,70)$, porém, não houve ajuste dos modelos de regressão até o quarto grau testado. Poucos estudos foram realizados sobre pectina total em frutos do bacurizeiro. Villachica et al. (1996) e Nazaré (2000) relataram o valor de 0,12\%. ET al

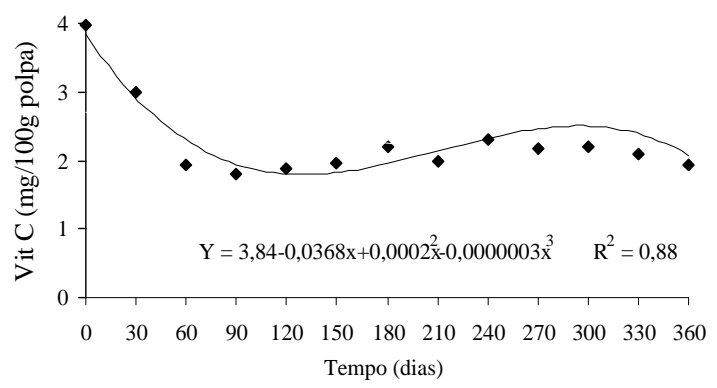

Figura 3 - Vitamina $\mathrm{C}$ da polpa de bacuri congelada durante 12 meses.
(2001) observou teores ligeiramente superiores, 0,27\% para frutos de epicarpo amarelo e $0,31 \%$ para os de epicarpo verde. Aguiar et al. (2008) encontrou valores de pectina total com média de $1,32 \%$ próximos aos encontrados nesse estudo (1,72\%). Fontenele et al. (2010), em seu estudo com bacuri em temperatura ambiente e de refrigeração encontrou valores de pectina total próximos aos encontrados nesse estudo com médias de $1,60 \%$ para os frutos a atmosfera ambiente e $1,03 \%$ para os armazenados em atmosfera modificada. Os teores de pectina solúvel tiveram variação com médias de $0,74 \%$ a 0,85\%, diferindo estatisticamente ao nível de $5 \%$ de significância com o tempo de armazenamento, porém, não houve ajuste dos dados. Esses valores estão dentro do intervalo reportado por Aguiar et al. (2008), cuja variação foi de $0,40 \%$ a $1,19 \%$. Teixeira et al. (2001) obteve $0,19 \%$ de pectina solúvel para frutos de epicarpo amarelo e $0,20 \%$ para os de epicarpo verde, valores bem inferiores aos encontrados nesse estudo $(0,83 \%)$. Dados sobre o teor de pectina solúvel em bacuri são quase inexistentes na literatura, salvo Teixeira et al. (2001) que relatou 0,19\%,

Tabela 2 - Médias de cor L, a, b, pectina total e solúvel, compostos fenólicos poliméricos (CFP) e oligoméricos (CFO) para a polpa de bacuri durante período de 360 dias de armazenamento.

\begin{tabular}{cccccccc}
\hline $\begin{array}{c}\text { Tempo } \\
\text { (dias) }\end{array}$ & Cor L** & Cor a & Cor b & $\begin{array}{c}\text { Pectina total } \\
(\%)^{* *}\end{array}$ & $\begin{array}{c}\text { Pectina } \\
\text { solúvel } \\
(\%)^{* *}\end{array}$ & CFP** & CFO** \\
\hline & & & & & & & \\
0 & $68,44 \pm 0,12$ & $-1,89 \pm 0,16$ & $11,59 \pm 0,06$ & $1,60 \pm 0,00$ & $0,75 \pm 0,02$ & $0,04 \pm 0$ & $0,03 \pm 0$ \\
30 & $68,55 \pm 0,22$ & $-1,84 \pm 0,04$ & $10,43 \pm 0,35$ & $1,59 \pm 0,00$ & $0,79 \pm 0,03$ & $0,05 \pm 0$ & $0,02 \pm 0$ \\
60 & $68,62 \pm 0,23$ & $-1,85 \pm 0,16$ & $11,45 \pm 0,16$ & $1,57 \pm 0,06$ & $0,73 \pm 0,08$ & $0,06 \pm 0$ & $0,02 \pm 0$ \\
90 & $69,43 \pm 0,27$ & $-1,89 \pm 0,03$ & $11,6 \pm 0,23$ & $1,66 \pm 0,06$ & $0,74 \pm 0,06$ & $0,07 \pm 0$ & $0,02 \pm 0$ \\
120 & $69,77 \pm 0,11$ & $-1,89 \pm 0,03$ & $11,45 \pm 0,16$ & $1,62 \pm 0,17$ & $0,77 \pm 0,05$ & $0,06 \pm 0$ & $0,02 \pm 0$ \\
150 & $69,14 \pm 0,13$ & $-2,11 \pm 0,10$ & $11,61 \pm 0,45$ & $1,60 \pm 0,05$ & $0,74 \pm 0,06$ & $0,07 \pm 0$ & $0,03 \pm 0$ \\
180 & $69,33 \pm 0,60$ & $-1,63 \pm 0,02$ & $11,46 \pm 0,22$ & $1,60 \pm 0,07$ & $0,68 \pm 0,10$ & $0,07 \pm 0$ & $0,03 \pm 0$ \\
210 & $67,39 \pm 0,63$ & $-1,67 \pm 0,10$ & $11,00 \pm 0,36$ & $1,84 \pm 0,10$ & $0,75 \pm 0,04$ & $0,06 \pm 0$ & $0,03 \pm 0$ \\
240 & $67,52 \pm 0,73$ & $-1,44 \pm 0,23$ & $10,63 \pm 0,21$ & $1,84 \pm 0,01$ & $0,82 \pm 0,01$ & $0,06 \pm 0$ & $0,03 \pm 0$ \\
270 & $70,95 \pm 0,61$ & $-1,72 \pm 0,11$ & $11,05 \pm 0,30$ & $1,78 \pm 0,00$ & $0,77 \pm 0,05$ & $0,06 \pm 0$ & $0,04 \pm 0$ \\
300 & $69,78 \pm 0,25$ & $-1,49 \pm 0,07$ & $11,64 \pm 0,06$ & $1,75 \pm 0,09$ & $0,83 \pm 0,01$ & $0,06 \pm 0$ & $0,05 \pm 0$ \\
330 & $69,85 \pm 0,34$ & $-1,88 \pm 0,14$ & $11,74 \pm 0,27$ & $1,81 \pm 0,09$ & $0,83 \pm 0,01$ & $0,06 \pm 0$ & $0,04 \pm 0$ \\
360 & $69,95 \pm 0,58$ & $-1,94 \pm 0,14$ & $11,77 \pm 0,09$ & $1,58 \pm 0,02$ & $0,81 \pm 0,01$ & $0,07 \pm 0$ & $0,03 \pm 0$ \\
$\bar{X} \pm \sigma * * *$ & $69,14 \pm 0,97$ & $-1,50 \pm 0,99$ & $11,34 \pm 0,41$ & $1,68 \pm 0,10$ & $0,77 \pm 0,04$ & $0,06 \pm 0,007$ & $0,03 \pm 0,008$ \\
\hline
\end{tabular}

\footnotetext{
* valores médios obtidos das três repetições.

** diferiu significativamente durante o armazenamento ( $\mathrm{p} \leq 0,05)$.

*** Média geral \pm desvio-padrão.
} 
em frutos obtidos na CEASA - PI, e Aguiar et al. (2008) que encontrou valores de pectina solúvel com média de $0,81 \%$ e Fontenele et al. (2010) que relatou valores de pectina solúvel em torno de $1,72 \%$. Neste estudo os valores de pectina solúvel variaram de 0,75 a $0,83 \%$.

Pelos resultados obtidos para compostos fenólicos observou-se variação na fração solúvel em água (poliméricos) e em metanol 50\% (oligoméricos) estatisticamente significativas com o tempo de armazenamento ao nível de 5\%. No entanto, não foi possível ajustar a regressão até o quarto grau testado. A fração solúvel em metanol puro (dímeros) apresentou aumento linear em função do tempo $(p<0,05)$ como mostrado na Figura 4.

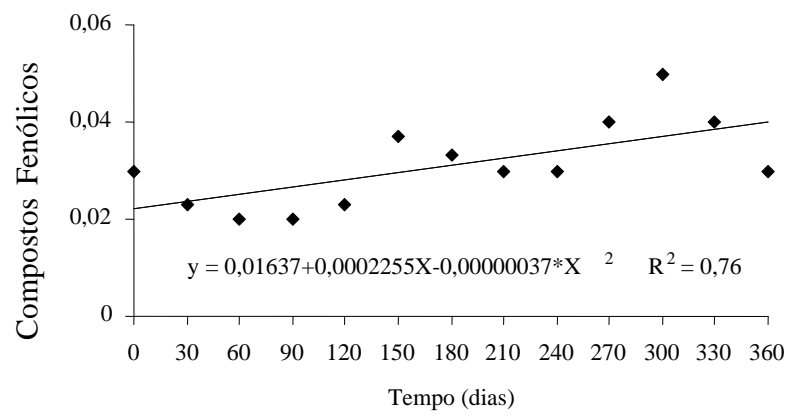

Figura 4 - Compostos Fenólicos Dímeros da polpa de bacuri congelada durante 12 meses.

Os valores de compostos fenólicos encontrados neste estudo foram baixos para todas as frações estudadas. Teixeira et al. (2001) afirma que este baixo teor pode ser decorrente, durante o amadurecimento, de condensações e degradações, que os tornaram adstringentes. $\mathrm{O}$ baixo teor dos compostos fenólicos mostra que os frutos do bacurizeiro utilizados neste experimento possuem baixa adstringência e esse é um fator positivo para o consumo in natura desse fruto, porém, não foi realizada análise sensorial que comprovasse essa baixa adstringência.

Os valores de $a^{*}$ e $b^{*}$ não variaram significativamente com o tempo ao nível de $5 \%$ de significância. A análise de regressão dos valores obtidos para o valor $\mathrm{L}^{*}$, em função do tempo de armazenamento mostrou existir diferença significativa $(\mathrm{p}<0,05)$ com o tempo, porém, verificou-se falta de ajuste para os modelos testados. De um modo geral, na polpa de bacuri estudada, ocorreu um ligeiro incremento nos valores de $\mathrm{L}^{*}$. Com isso, pode-se perceber que a polpa apresentou uma menor tendência ao escurecimento.
Os resultados das análises microbiológicas permitiram evidenciar que as amostras de polpa de bacuri submetida ao congelamento apresentaram qualidade satisfatória, de acordo com os atuais padrões de identidade e qualidade para polpa de frutas estabelecida pela Portaria $\mathrm{n}^{\circ} 01$ de 07 de julho de 2000 do Ministério da Agricultura e do Abastecimento (Brasil, 2000) e pela RDC N ${ }^{\circ} 12$ de 02 de janeiro de 2001 da Agência Nacional de Vigilância Sanitária (Brasil, 2001). Isso pode ser constatado, uma vez que, não foram evidenciadas contagem de bolores e leveduras, microrganismos aeróbios mesófilos, coliformes totais e coliformes a $45^{\circ} \mathrm{C}$ $(\mathrm{NMP} / \mathrm{g}<3)$. A presença de Salmonella sp. também não foi detectada em nenhuma das amostras analisadas.

\section{CONCLUSÕES}

A polpa apresentou boa estabilidade microbiológica durante o período de armazenamento estudado, indicando que foi processada em adequadas condições higiênicas e sanitárias que contribuíram para a obtenção de produtos microbiologicamente seguros.

A polpa de bacuri apresentou pequenas variações nas características físicas e químicas, durante o período de armazenamento avaliado. Os parâmetros de atividade de água, $\mathrm{pH}$ e coordenadas $\mathrm{a}^{*} \mathrm{e}$ b* não foram significativamente afetados com o tempo de armazenamento.

A polpa apresentou baixos teores de vitamina $\mathrm{C} \mathrm{e}$ de compostos fenólicos, sendo estes últimos responsáveis pela adstringência e, nesse caso, a polpa apresentou-se própria para o consumo in natura e processamento industrial.

\section{AGRADECIMENTOS}

À Universidade Federal do Ceará, Embrapa Agroindústria Tropical, Conselho Nacional de Desenvolvimento Científico e Tecnológico CNPq pelo apoio na realização deste trabalho.

\section{REFERÊNCIAS BIBLIOGRÁFICAS}

AGOSTINI-COSTA, T.S. et al. Efeito do congelamento e do tempo de estocagem da polpa de acerola sobre o teor de carotenóides. Revista Brasileira de Fruticultura, Jaboticabal, v.25, n.1, p.56-59, 2003.

AGUIAR, L.P. et al. Caracterização física e físicoquímica de frutos de diferentes genótipos de bacurizeiro (Platonia insignis Mart.). Ciência e Tecnologia de Alimentos, Campinas, v.28, n.2, jun. 2008. 
ALVES, S. de M.; JENNINGS, W.G. Volatiles composition of certain Amazonian fruits. Food Chemistry, London, v.4, p.149-159, 1979.

\section{AMERICAN PUBLIC HEALTH ASSOCIATION. Compendium of methods for the microbiological examination of foods. Washington, 2001. 676p.}

\section{ASSOCIATION OF OFFICIAL ANALYTICAL} CHEMISTRY. Official methods of Analysis of the Association of Official Analytical Chemistry. 15.ed. Washington, 1992.2v.

BEZERRA, G.A.S. et al. Influência da adição de sacarose na estabilidade da polpa de bacuri conservada por métodos combinados. Ciência e

Agrotecnologia, Lavras, v.30, n.4, ago. 2006.

BRASIL. Ministério da Agricultura, Pecuária e Abastecimento. Instrução Normativa n. 01, de 7 de janeiro de 2000. Aprova padrões de identidade e qualidade para polpas de frutas. Diário Oficial [da] República Federativa do Brasil, Brasília, p. 54, 10 jan. 2000. Seção I.

BRASIl. Agência Nacional de Vigilância Sanitária. Resolução RDC n ${ }^{\circ}$ 2, de 2 de janeiro de 2001.

Regulamento Técnico sobre padrões microbiológicos para alimentos. Diário Oficial da União, Brasília, 10 jan. 2001.

BRASIL. Ministério da Saúde. Agência Nacional de Vigilância Sanitária. Métodos físico-químicos para análise de alimentos. Brasília, 2005. 1018p.

BUENO, S.M. et al. Avaliação da qualidade de polpas de frutas congeladas. Revista do Institito Adolfo Lutz, São Paulo, v.62, n.2, p.121-126, 2002.

CAVALCANTE, P.B. Frutas comestíveis da Amazônia. 6.ed. Belém: CNPq/Museu Paraense Emílio Goeldi, 1996. 279p.

CHITARRA, A.B.; CHITARRA, M.I.F. Pós-colheita de frutos e hortaliças: fisiologia e manuseio. 2.ed. rev. e ampl. Lavras: UFLA, 2005. 785p.

FERREIRA, F.R.; FERREIRA, S.A. do N.; CARVALHO, J.E.U. de. Espécies frutíferas pouco exploradas, com potencial econômico e social para o Brasil. Revista Brasileira de Fruticultura, Cruz das Almas, v.9, p.11-22, 1987.

FONTENELE, M.A.; FIGUEIREDO, R.W.; MAIA, G.A.; ALVES, R.E.; SOUSA, P.H.M. de; SOUZA, V.A.B. de.
Conservação Pós-Colheita de Bacuri (Platonia insignis Mart.) sob Refrigeração e Embalado em PVC. Revista Ceres, Viçosa, v.57, p.292-296, 2010.

HUNTERLAB. Applications note: CIE L* a* b* color scale. Virginia, 1996.

MILLER, G.L. Use of dinitrosalicylic acid reagent for determination of reducing sugars. Analytical Chemistry, Washington, v.31, p.426-428, 1959.

NAZARÉ, R.F.R. de. Produtos agroindustriais de bacuri, cupuaçu, graviola e açaí, desenvolvidos pela Embrapa Amazônia Oriental. Belém: Embrapa Amazônia Oriental, 2000. 27p. (Embrapa Amazônia Oriental, 41).

PEREIRA, L.V.; ABRAHÃO, E.; ANDRADE. J.C.de; FRÁGUAS, J. C.; ALVARENGA.A.A. Análise do mercado de frutas em Lavras-MG. Ciência e Agrotecnologia, Lavras, v. 32, n. 6, p. 1981-1984, nov./ dez., 2008.

PIENIZ, S.; COLPO, E.; OLIVEIRA, V.R.de; ESTEFANEL, V.; ANDREAZZA,R.Avaliação in vitro do potencial antioxidante de frutas e hortaliças. Ciência e

Agrotecnologia, Lavras, v. 33, n. 2, p. 552-559, mar./ abr., 2009.

PIMENTEL GOMES, F.P. O bacuri. In: Fruticultura brasileira. São Paulo: Nobel, 1978. p.107108.

REICHER, F.; SIERAKOWSKI, M.R.; CORRÊA, J.B.C. Determinação espectrofotométrica de taninos pelo reativo, fosfotúngstico-fosfomomolíbdíco. Arquivos de Biologia e Tecnologia, Curitiba, v.24, n.4, p.401-411, 1981.

SOUZA, V.A.B. de.; ARAÚJO, E.C.E.; VASCONCELOS, L.F.L.; LIMA, P.S. da C. Variabilidade de características físicas e químicas de frutos de germoplasma de bacuri da Região Meio-Norte do Brasil. Revista Brasileira de Fruticultura, Jaboticabal, v.23, n.3, p.677-683, 2001.

SOUZA, V.A.B. de; VASCONCELOS, L.F.L.; ARAÚJO, E.C.E.; ALVES, R.E. Bacurizeiro (Platonia insignis Mart.). Jaboticabal: Funep, 2000. 72p. (Série Frutas Nativas, 11). 
STROHECKER, R.; HENNING, H.M. Analisis de vitaminas: métodos comprobados. Madrid: $\mathrm{Paz}$ Montalvo, 1967. 428p.

SWAIN, T.; HILLIS, E.E. The phenolic constituens of Prunus domestica: II., the analysis of tissues of the 'victoria' plum tree. Journal of the Science of Food and Agriculture, London, v.10, n.2, p.135-144, 1959.

TEIXEIRA, G.H.A.; DURIGAN, J.F.; ALVES, R.E.; FILGUEIRAS, H.A.C.; MOURA, C.F.H. Frutos do bacurizeiro (Platonia insignis Mart.): caracterização, qualidade e conservação: I. análises químicas e bioquímicas. Revista Brasileira de Fruticultura, Jaboticabal, v.23, n.1, p.116-120, 2001.

UNIVERSIDADE FEDERAL DE VIÇOSA. SAEG Sistema para Análises Estatísticas. Versão 9.1. Viçosa, MG: Fundação Arthur Bernardes, 2007.

VILLACHICA, H. et al. Frutales y hortaliças promossoras de la Amazônia. In: Tratado de Cooperación Amazônica. Lima: Secretaria Pró-Tempore, 1996. p.152-156. (Publicaciones, 44).

YAMASHITA, F. et al. Produtos de acerola: estudo da estabilidade de vitamina C. Ciência e Tecnologia de Alimentos, Campinas, v.23, n.1, p.92-94, 2003. 